\title{
Specialists without spirit: crisis in the nursing
} profession

\author{
Soma Hewa and Robert W Hetherington University of British Columbia and University of Alberta, Canada
}

\section{Authors' abstract}

This paper examines the crisis in the nursing profession in Western industrial societies in the light of Max Weber's theory of rationalisation. The domination of instrumental rational action in modern industrial societies is evident in the field of modern medicine. The burgeoning mechanistic approach to the human body and health makes modern health care services increasingly devoid of human values. Although the nursing profession has been influenced by various changes that took place in health care during the last few decades (for example greater reliance on technology), the underlying values of the nursing profession still emphasise a broad definition of the well-being of patients. Hence, in recent years the irrational consequences of growing technological medicine in North America has resulted in a serious crisis in the nursing profession. To resolve this crisis the authors propose a reorganisation of modern health care services on the basis of a new paradigm which is compatible with both the health care needs of the people and the main emphasis in education and training of the nursing profession.

Classical sociological theorists provide an excellent framework for interpretation of modern social issues. One such theorist, a founding father of modern sociology, is Max Weber. A major emphasis in Weberian theory is the examination of the development of modern Western social and economic institutions arising from the influence of the Reformation. Weber recognised the Reformation as a turning point for modern Western civilisation, breaking away from the dominant influence and teaching of the Catholic Church. The unique characteristic of modern Western civilisation, according to Weber, is the process of rationalisation which began with the sixteenth and seventeenth century Reformation. Rationalisation, for Weber, involved turning away from traditional ways of thinking, toward the logical application of rational thought. This process freed the individual to define his/her own destiny, and to choose rationally amongst

\section{Key words}

Nursing ethics; rationalisation; mechanistic model; nursing values; health care paradigms; technology. various alternative courses of action to attain desired ends. It also resulted in demystification of many things? in society, and developed the belief that problemscould be solved by logical intervention rather thano appeal to higher powers.

Weber referred to rationalisation as 'instrumental rational action' which he defined as

'...based on purely rational choice among possible means to obtain certain defined goals. Hence, one chooses the means methodically and rationally in view of a specific goal and in this context, values maxe become obstacles to achievement of the goal' (1).

The last part of Weber's definition of instrumenta rational action suggests the emergence of a paradox that is, the very achievement of goals through rationa action may result in erosion of values. In recent years $\mathbb{R}$ a number of scholars have tried to draw attention to this paradox in Weber's theory $(2,3,4)$. The purpose of this paper is to pursue the paradox of rationalisation in? terms of some 'irrational' outcomes in modern Western? capitalist social structure, particularly with reference to the dominant system of health care. Weber himself foresaw the paradox, the 'irrationality', in his famous metaphor of the 'iron cage' where he referred to the destruction of fundamental social values in the face of growing rationalisation.

This destruction of social values has resulted in $f$ serious crisis in health care. For instance, in th nursing profession there are indications of a conflice. between the process of rationalisation and fundamentah values traditionally associated with the profession. It is argued here that growing pressures to implement of mechanistic medical model in nursing tend tow undermine such basic values of the nursing profession and lead to job dissatisfaction, stress, frustration and confrontation between nurses, physicians and health care administrators. To resolve this crisis in nursing, the professional values of nursing themselves must be re-established on the basis of its original paradigm $\stackrel{+}{\Phi}$ The cornerstone of the original nursing paradigm as developed by Nightingale and others, was to provide humanitarian caring for the sick and the disabled (5)D This approach did not make a distinction between physical, psychological, social and spiritual aspects of 
human existence, but rather treated them together in a holistic fashion.

\section{Disenchantment of the world}

As suggested earlier, the manner in which instrumental rational action dominates modern Western societies was foreseen by Max Weber. Instrumental rational action, Weber contended (1) is based on a purely rational choice amongst possible means to attain certain defined goals. Hence, one chooses the means methodically and rationally in view of a specific goal. He argued that one outcome of this rationalisation is a 'disenchantment of the world' which has taken place in the West more than anywhere else. This means that virtually all spheres of Western culture and social organisation have undergone the process of rationalisation, so that in principle, there are no mysterious unknowable powers and humans can master everything through technical and practical means. In The Protestant Ethic and the Spirit of Capitalism (6), Weber defined the process of rationalisation as ideational intentionality - that is, humans are not at the mercy of historical forces that they do not control. In action which is purposiverational, every individual has prior knowledge of his/ her action, and therefore, outcomes of such actions are predictable. That is, individuals are always capable, according to Weber, of eradicating irrational consequences of their own actions by choosing alternative courses of action which will counteract untoward outcomes and which are compatible with desirable political and social conditions.

Weber believed that people create their own history, and that they have sufficient freedom to do so. In this regard, Weber believed that the Marxist interpretation of history has made an important contribution (6) in that Marx emphasises the autonomy of conscious individual action in the unfolding of historical development. On this point, Marx and Weber are in agreement. Rationality, according to Weber, is the freedom to accomplish what is desirable for the individual, even when such freedom may result in the undermining of values of the larger social system. The means and ends of such action may not always be socially acceptable, but insofar as the individual's purpose is concerned they are rational. The rational consideration of the given means in relation to the selfpostulated purpose, and the relation of the purpose itself to the chances and results of its attainment, constitute the responsibility of free and rational conduct (7). The implications of rationality, as defined by Weber, include such outcomes as calculability, predictability, freedom of choice and practicality (efficiency), which are all fundamental elements of modern industrial capitalism. Thus, rational action is the freedom to pursue any goal which is attainable by calculable, predictable and practical means freely chosen. It is emphasis on these 'means' that is described by Weber as being rational in modern industrial society.
Weber realised, however, that the process of rationalisation would have adverse effects on human values in the West by eliminating the sense of duty based on values which binds individuals together $(8,9)$. In concluding his well-known lecture on Science as a Vocation in 1918 at the University of Munich, Weber pointed out this paradoxical nature of the process of rationalisation in modern Western societies. 'The fate of our times' Weber maintained (10), 'is characterised by rationalisation and intellectualisation and, above all, by the disenchantment of the world. Precisely the ultimate and most sublime values have retreated from public life either into the transcendental realm of mystic life or into the brotherliness of direct and personal human relations'. Modern Western societies, according to Weber, are moving, towards an inescapable danger (iron cage) from which they can never be rescued: the impossibility of preserving human values in the face of scientific rationalisation. Weber said:

'...for the last stage of this cultural development it might well be truly said: specialists without spirit, sensualists without heart, this nullity imagines that it has attained a level of civilisation never before achieved' (6).

This is the end of Western industrial civilisation, as Weber foresaw it.

\section{The Cartesian paradigm in modern medicine}

The penetration of instrumental rational action into modern industrial societies has been a distinctive feature of the West. This is specifically true in the field of modern medicine. It should be emphasised, however, that medicine did not develop in a humanitarian vacuum: efforts of the medical profession throughout history were driven primarily by a desire to alleviate the suffering of mankind. The orientation of medicine throughout history has been to seek solutions to the suffering of mankind through technological advances which concentrated on viewing the body as a mechanical system in need of repair (for example, the work of Robert Koch, Louis Pasteur). There were competing paradigms to the dominant paradigm, such as that advocated by such important figures as Virchow and Engels, but these paradigms were not successful in gaining dominance in the field of medicine.

According to Sheila Hillier (3) the development of a mechanistic approach to the human body in modern medicine originated with the discovery of the circulation of the blood by William Harvey (11) in the early seventeenth century. Harvey's discovery was later supplemented by the publication of the Treatise on Man (12) by Rene Descartes, in which the human body was clearly separated from the mind. Cartesian dualism recognised the human body as analogous to the machine which is composed of separate but interdependent parts (13). This mechanistic view of 
the human body grew apace with subsequent discoveries in medicine which reinforced the view that illnesses are results of the failure of mechanical functions of various parts of the human body. As Hillier argues, rationalisation in the West furthered the development of a mechanistic paradigm in modern medicine which contradicts the traditional view of the nature of humans.

Within this paradigm it is believed that technical progress in medicine will somehow resolve all health problems. This belief, as Ray Jackson argues (14), is emphasised particularly by medical specialists whose skills are based on the use of modern medical technologies, and who attempt to master human life through technology. Paul Starr (15) goes as far as to recognise a medical industrial complex (composed of doctors, hospital managers, health insurance companies and medical technology manufacturers) emerging as a result of the dominance of the mechanistic paradigm in health care.

The paradoxical nature of technological growth in modern medicine has resulted in the one-dimensional character of the contemporary health care system. Health care services are increasingly devoid of human relations (16), and individual patients are treated without regard for psychological, social and cultural differences. It is a common belief among physicians that medicine is a science and humans are complicated machines that break down. Everything that happens to a patient can be explained in scientific terms. Psychology, spirituality and emotions are not regarded as important aspects of medicine, nor are they part of medical jargon. Therefore, aspects of the patient's problems which are accessible to scientific intervention and analysis will take priority, while those aspects which are less well comprehended (emotions, spirituality, social well-being) are likely to be ignored. This results in doing what is technologically possible, rather than in doing what may be in the best interests of the patient, all things considered.

The persistent emphasis on technical aspects of health care services has led to tensions between the nursing profession and physicians, patients and physicians, and the nursing profession and health care management. These tensions are clear examples of the irrational outcomes of growing rationalisation (instrumental rational action).

In the following section, we discuss the major presuppositions of the nursing profession and how they conflict with the assumptions of the mechanistic paradigm in medicine.

\section{Nursing: trapped in the iron cage}

It can be argued that both medicine and nursing had religious, spiritual or metaphysical origins. In medicine, such origins continued to have dominant influence over the thinking of practitioners roughly until the seventeenth century. However, following the Reformation, medical scientists such as Harvey began to question the religious and metaphysical bases of the human body and explanations of health. Direct observation and experimentation became an accepted procedure in medical science and teaching. Such scientific approaches slowly discredited the traditional intepretations in medicine, and tended to change the general orientation of medicine to a more mechanistic one. Subsequent discoveries and their success supported the idea that the body could be understood and treated as a series of interrelated mechanical parts.

Unlike medical science which grew towards a more mechanistic view of the human body and health, nursing from its inception maintained a totally different perspective on health care. One of the most important reasons for this difference is that nursing emerged as a secular occupation from a religious background. Even though both nurses and physicians worked in the same environment, this difference remained. From the beginning, nursing was influenced by Judaeo-Christian values which shaped the occupational goals of the profession. As the majority of nurses working in hospitals during the early part of the nineteenth century were Roman Catholic nuns, their services were generally regarded as a humanitarian gesture towards the poor, sick and disabled segments of society on the part of the Church. Also, such tasks provided spiritual satisfaction for nurses who believed that helping the diseased and les fortunate was the most appropriate means of attainin salvation (17).

The reorganisation of modern nursing in the nineteenth century was initiated by Florence Nightingale who believed that nurses were capable of providing care for the sick and the poor in a more organised and professional manner than was the custom (18). However, the prime motivation that led Nightingale to reorganise nursing stemmed from her strong commitment to the Judaeo-Christian belief system. She felt she had been called by God to the service of the poor and the sick and thus despite the strong opposition of her middle-class family, Nightingale pursued her vision until she and her fellow gentlewomen were given formal status in the health care system by the authorities. Her struggle to gain recognition for nursing was by no means an effort to create an independent profession of nursing in the system of health care delivery. Therefore, as Linda Aiken (19) argues, nursing from the beginning or attempted to accomplish two fundamental goals: first, $N$ for nursing to become an ancillary medical occupation, $\mathbb{W}$ dedicated to maintaining the comfort and well-being of the sick and the disabled; second, for nurses to become obedient and disciplined assistants to physicians, and to be involved in hospital ward organisation and $\stackrel{\oplus}{\oplus}$ management.

In contrast to the medical profession which grew more attached to the mechanistic paradigm because of $\stackrel{\Phi}{\Phi}$ scientific and technological discoveries in medicine, $\stackrel{\mathbb{Q}}{\stackrel{\circ}{\circ}}$ nursing somehow managed to continue to emphasise $\bar{\sigma}$ its fundamental ideals of humanitarian concern for patients (20). Hence, despite the mechanistic view 
dominating medicine, nursing remained within the traditional (original) paradigm. Although 'nursing' as a secular occupation became involved with various changes that took place in health care in modern industrial societies (for example, greater reliance on technological devices), the underlying values of the nursing profession still emphasise a broad definition of the well-being of patients (21). Hence in recent years the growing emphasis on technological medicine in North America has resulted in a serious crisis in the nursing profession (see for example 22,23,24).

While the medical profession and health care administrators are attempting to expand the utilisation of technological devices in medicine, members of the nursing profession are striving to cope with their humanitarian consequences. Therefore, nurses are trapped between two competing paradigms. They are obedient assistants to physicians and are under pressure to follow the mechanistic approach to health and illness, since they must provide care on order from physicians. Further, the care that they provide now for the most part involves mechanised care. In other words, much of their work involves specialised technical tasks which require monitoring the performance of some mechanical support or diagnostic system. Thus, there is little opportunity for initiative on the part of nurses. They are not able to respond to the suffering or the needs of the patients; rather they are forced to respond to the needs of the physicians and the mechanical systems in which they have become enmeshed. This leads directly to a fundamental contradiction, a 'feeling of disappointment with career and professional development as well as a disappointment over the ability to fulfill professional norms' (25).

Although academic and professional training in nursing still emphasises social and humane aspects of life (26), once nurses become part of the health care system their task suddenly becomes subordinated to the mechanistic paradigm of medicine. They have little voice in determining the nature of their services, and they have little participation in the process of decisionmaking. Physicians decide who should receive what services even though the nurses often have to face the day-to-day realities of patient suffering. Nurses work in a two-dimensional world. In one dimension the view held by physicians and hospital management is more concerned with the application of mechanistic solutions to medical problems (curing the illness). In the other dimension, nurses are concerned not only with applying mechanical solutions but also with caring for the total well-being of the patient (including psychological and physical comfort) and thus emphasising traditional, fundamental values of the nursing profession.

As in any other area of life in modern industrial society, health care has been experiencing a wide range of technological revolutions. The most salient aspect of modern medical organisation is the extent to which physicians have divided themselves into specialties which are the result of growing technological and scientific innovations (27). These specialties are largely independent of one another and each specialty has little knowledge of other areas that are not included in that specialty. This fragmentation encourages specialists to make decisions on various health care services that do not take into account the 'whole patient', including her/his social, cultural, emotional and psychological characteristics. The process of specialisation and the development of technological solutions to problems is, on the surface, a rational approach. However, when rationalisation becomes dogma, as is the tendency in modern society, then the approach may be applied indiscriminately and at the expense of other considerations which consequently go without attention. Then rationalisation becomes 'irrational' (28).

By contrast, nursing programmes are still based on the fundamental idea that the first and foremost responsibility of medical care is to treat the patient as a total human being. Nursing students are taught basic disciplines in the fields of social sciences and humanities along with the major nursing coursework and training. Courses such as sociology, psychology, philosophy and religious studies are compulsory in many nursing programmes. Programmes such as these are designed to produce educated humanitarian servants dedicated to the well-being of the sick and disabled as it was originally conceived by Nightingale. When these values are being threatened by the irrational consequences of the mechanistic approach to health, nurses become helpless and disappointed with their occupations.

\section{Nightingale revisited}

Weber's analysis of the process of rationalisation in modern industrial society predicted that scientific and technological progress may produce experts in scientific disciplines, but the process of rationalisation cannot produce scientifically ascertainable ideals. Therefore, scientific and technological progress, characterised by the process of rationalisation, is a mixed blessing. The 'disenchantment' of the world has eliminated all mysterious and unknowable interpretations of life by providing rational, scientific solutions to life events. But it also usurps fundamental values that assure the very survival of humanity. The price of scientific and technological progress is that the value of humanity is depreciated ${ }^{1}$. In such a system, it is conceivable that the social and economic value of individuals will determine who receives care. In the narrow sense, this is a rational approach; why, after all, should more funds be expended on an individual than can be demonstrated in terms of his/her social worth? It is, however, 'irrational' in the sense that such an approach does not take into account other aspects of human life, and the basic human value that life itself is beyond economic and social valuation.

The crisis in nursing is a reflection of the attack on fundamental values by growing instrumental rational 
systems of action - that is, the penetration of a mechanistic approach into health and medicine. Those who cling to basic human values, such as members of the nursing profession, are trapped between competing paradigms. The process of rationalisation de-emphasizes the ideals of the nursing profession which have persisted throughout history. Their work has lost meaning under the present circumstances, largely due to the devaluation of the kind of work they do in a highly technological context. This devaluation is based upon the fact that non-technologicallyorientated patient-care work cannot be legitimised in terms of the scientific, mechanistic paradigm which dominates medical care today.

The solution to this crisis should be based on the health care needs of the people rather than on the basis of political struggles among competing power groups. Thus, the question one must ask is, what is the state of health care needs in modern industrial societies? Given the present status of health in these societies, there is little demonstrable benefit to be gained from further expansion of the mechanistic paradigm (29). The health care needs of the vast majority are primarily of such a nature that they require services defined by a new paradigm. In this new paradigm, there must be a reuniting of the body and the mind, but 'mind' must be expanded to encompass social, economic and cultural aspects of human existence.

The new specialists who would provide services within this model undoubtedly will undergo a radically different type of education and orientation from that which currently is stressed in medical schools. Reaching out to embrace the challenges of the new model will involve imagination and tolerance for uncertainty. It is a 'new way of seeing' reality, which is at the basis of the Kuhnian paradigm for scientific revolution (30). It seems entirely likely that, under the aegis of this revolution, the nursing profession will find itself in a leadership role, given that the emphasis of the profession over time leads naturally towards the embracing of a more encompassing view of human life and health.

In Weberian theory, it is predicted that social paradigms must always be consistent with societal needs (7). The pursuit of action within specific paradigms occurs with the blessing (legitimisation) of society as a whole. Such blessing is incrementally withdrawn, according to Weber, as overall benefits to society of those actions is demonstrably declining. Ongoing trends in health care needs in modern industrial society indicate the inevitable decline of the mechanistic paradigm and the equally inevitable rise to prominence of a new paradigm more suited to the needs of the people. In the new model, there will be little place for specialists without spirit.

Soma Hewa BA, MA, PhD is Lecturer in sociology, University of British Columbia, Vancouver, Department of Sociology and Anthropology. Robert W Hetherington $B A, M A, P h D$ is Professor, Department of Sociology,
University of Alberta, Edmonton.

\section{References}

(1) Weber M. The theory of social and economic organization. Translated by Henderson A R. New York: Oxford University Press, 1947: 115-117.

(2) Turner B. The rationalization of the body: reflections on modernity and discipline. In: Lash S, Whimster S, eds. Max Weber: rationality and modernity. London: Allen and Unwin, 1987: 222-241.

(3) Hillier S. Rationalism, bureaucracy and the organization of health services: Max Weber's contribution to $\overrightarrow{\vec{\omega}}$ understanding modern health care systems. In: $\omega$ Scrambler G, ed. Sociological theory and medical sociology. London: Tavistock, 1987: 194-220.

(4) Gronow J. The element of irrationality: Max Weber's $\overrightarrow{\vec{D}}$ diagnosis of modern culture. Acta sociologica 1988; 31: 319-331.

(5) Simpson R L, Simpson I H. Women and bureaucracy in $\widehat{V}$ the semiprofessions. In: Etzioni A, ed. The 0 semiprofessions and their organization: teachers, nurses and social workers. New York: The Free Press, 1969: 196265.

(6) Weber M. The Protestant ethic and the spirit of capitalism. Translated by Parsons T. New York: Scribner, 1958: 24.

(7) Weber M. Gesammelte aufsatze zur wissenschaftslehre. Hrsg Winckelmann J. Tubinen: J C B Mohr 1951: $44 \mathrm{~B}$

(8) Weiss J. On the irreversibility of Western rationalization and Max Weber's alleged fatalism. In: Lash Whimster S, eds. Max Weber: rationality and modernit London: Allen and Unwin, 1987: 154-163.

(9) Hennis W. Personality and life orders: Max Weber's theme. In: Lash S, Whimster S, eds. Max Weber: rationality and modernity. London: Allen and Unwin, 1987: $52-74$.

(10) Weber M. Max Weber: essays in sociology. Translated by Gerth H, Mills C W. New York: Oxford University Press, 1946.

(11) Harvey W. Anatomical studies on the motion of the heart and blood. Translated by Leake C. Springfield: Charles Thomas, 1928.

(12) Descartes R. Treatise on man. In: Cottingham, J, Stoothoff R, Murdoch D, translators. The philosophical writings of Descartes, volume 1. Cambridge: Cambridge 윽 University Press, 1985: 99-108.

(13) Figlio K. The historiography of scientific medicine: an $\mathrm{O}$ invitation to the human sciences. Comparative studies in society and history 1977; 19: 262-286.

(14) Jackson R. Issues in preventive health care. Ottawa: Science Council of Canada 1985.

(15) Starr P. The social transformation of American medicine. New York: Basic Books, 1982.

(16) Bohme G. Midwifery as science: an essay on the relation $\omega$ between scientific and everyday knowledge. In: Stehr $\underset{<}{\sigma}$ N, Meja V, eds. Society and knowledge. New Brunswick: $\bullet$ Transaction Books, 1984.

(17) Freidson E. Profession of medicine. New York: Dodd, $\stackrel{\mathscr{\leftrightarrow}}{+}$ Mead, 1970.

(18) Woodham-Smith C. Florence Nightingale: 1820-1910. New York: McGraw-Hill, 1951.

(19) Aiken L H. Nurses. In: Mechanic D, ed. Handbook of $\frac{\stackrel{P}{D}}{\mathrm{Q}}$ health, health care and the health professions. New York: Free Press, 1983: 407-431.

(20) Simpson I H. From student to nurse: a longitudinal study of 
socialization. New York: Cambridge University Press, 1979.

(21) Curreri C A, Gilley W F, Faulk L, Swansburg R C. Job satisfaction: hospital-based RNs versus home health care RNs. Nursing forum 1985; 22: 125-134.

(22) McCranie E W, Lambert V A, Lambert C E Jr. Work stress, hardiness, and burnout among hospital staff nurses. Nursing research 1987; 36: 374-378.

(23) Bryson R W, Aderman M, Sampiere J M, Rockmore L, Takayoshi $M$. Intensive care nurses: job tension and satisfaction as a function of experience level. Critical care medicine 1985; 13: 767-768.

(24) Marshall R, Kasman C. Burnout in the neonatal intensive care unit. Pediatrics 1980; 65: 1161-1165.

(25) Dean D. Alienation: its measurement and meaning. American sociological review 1967; 26: 753-758.

(26) Olesen V L, Whittaker E W. The silent dialogue. San Francisco: Jossey-Bass, 1968.

(27) Mechanic D. Physicians. In: Mechanic D, ed. Handbook of health, health care and the health professions. New York: Free Press, 1983: 432-454.

(28) Ellul J. The technological society. New York: Vintage
Books, 1965.

(29) Engel G L. The need for a new medical model: a challenge for biomedicine. Science 1977; 196: 129-135.

(30) Kuhn T. The structure of scientific revolution. Chicago: University of Chicago Press, 1960.

\section{Footnote}

1. It should be noted, however, that in modern Western societies, instrumental rational action has been used to protect fundamental values. For example, the introduction of Canadian and British national health insurance programmes has ensured every citizen of the society the right to receive health care regardless of social class, ethnicity, gender, religion, etc. This is a legislated (ie legal-rational) guarantee of human rights, thus a protection of fundamental human values. Another example is the institution of the Charter of Rights and Freedoms in Canada, and the Bill of Rights in the United States. These are basically examples of the application of instrumental rational action in creating rational-legal institutions which guarantee human values will be respected. 